\title{
ANALYSIS OF THE BEHAVIOR IN THE WIND TUNNEL OF AN EXPERIMENTAL MODEL OF SAVONIUS WITH INTERLOCKING CUPS WITH THE CLASSIC ONES WITH 2, 3 AND 4 SEMI- CYLINDRICAL CUPS
}

\author{
Nelu CAZACU \\ "Dunărea de Jos" University of Galaţi, Romania \\ e-mail:nelu.cazacu@ugal.ro
}

\begin{abstract}
The paper is based on experiments conducted on the wind tunnel at low wind speeds $(<9.5 \mathrm{~m} / \mathrm{s})$, on an experimental model of $S$-rotor wind turbine type with four blades and a D/H ratio of 1 . Semi-cylindrical cups opposite 180 degrees are aerodynamically coupled by overlap and with an air passage gap to equalize the pressures. The formed channel is shaped to allow the same for pairs of blades at 90 degrees. The experimental model has an area of $0.025 \mathrm{~m}^{2}$ which represents $10 \%$ of the surface of the measuring section of the wind tunnel $\left(0.25 \mathrm{~m}^{2}\right)$. The behavior of the experimental model was compared with the experimental models of S-rotor with 2, 3 and 4 semi-cylindrical cups, with the same interception surface. The results confirm the better start of the experimental model by reducing dead zones and operating more evenly and stably over a longer range of wind speeds. The results confirm the validity of the proposed concept of interwoven aerodynamic coupling of semi-cylindrical cups.
\end{abstract}

KEYWORDS: Savonius rotor, S-rotor, low wind, experimental model

\section{Introduction}

The work is part of the concerns to design and build a Savonius type wind turbine to be characterized by: operation at low wind speeds, independence of wind direction, uniform torque at the shaft, the ability to take wind gusts specific to the urban area. Such a turbine could be integrated in the polygeneration system described in $[1,2]$. But in the SE region of Romania there are areas for which the wind has average annual speeds higher than $9 \mathrm{~m} / \mathrm{s}$, which makes it possible to include a wind turbine with a vertical axis of Savonius type as an alternative energy source. Also, a very strong wind protection system is needed, a system that is not part of this work.

In the paper [3] were presented the experimental conditions, the results of the experiments performed in the wind tunnel from the laboratory's laboratory of materials for alternative energy sources. The results show that the number of semi-cylindrical buckets used to make experimental models of vertical axis wind turbines (VAWT) of S-rotor type (Savonius) have an important influence on the behavior of experimental models. Important differences are for the situations when the experimental model had 2, 3 or 4 cups. The use of 5 or 6 buckets is no longer of interest due to the increase of the intersection surface of the boom without producing useful torque to the shaft. We mention that the tests performed in the wind tunnel were made in the conditions in which there were no mechanical loads, other than the friction in the bearing bearings.

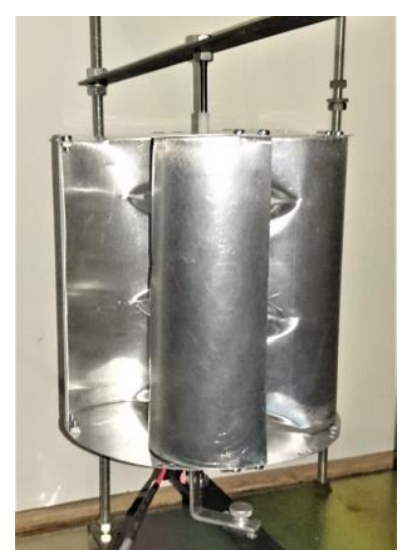

Fig. 1. Image with the experimental model S2PCiNL 
The increase of the number of blades from minimum 2 to VAWT of Savonius type aims to avoid the situation of blocking the wind turbine in the position with the basic plane of the buckets in the wind direction and the uniformity of the torque [4]. Savonius-type VAWT starters with two semicylindrical buckets can also be cumbersome if the buckets are in a different position than the maximum torque. Various methods to improve torque uniformity and starting have been tried as is the paper [5].

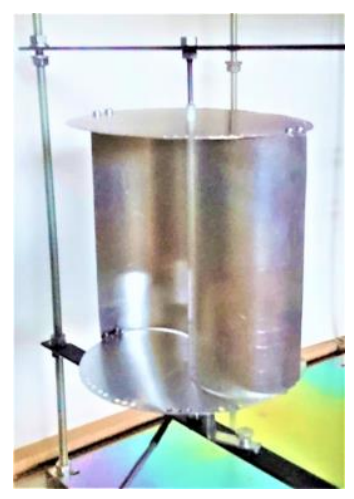

Fig. 2. Image with the S2CNL experimental model

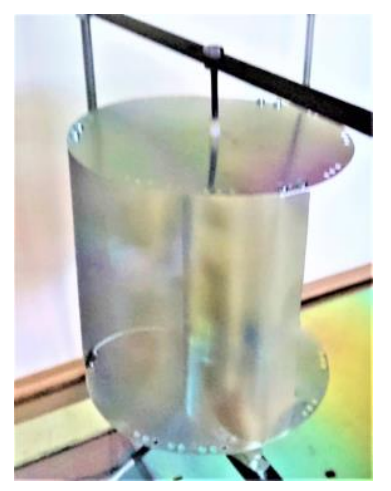

Fig. 3. Image with the S3CNL experimental model

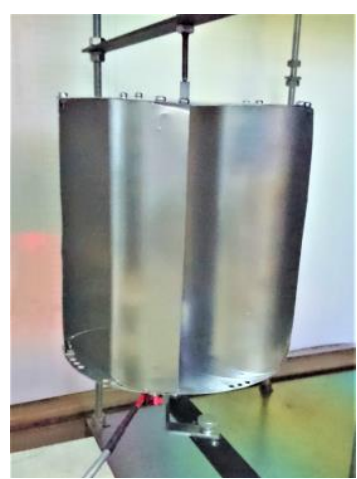

Fig. 4. Image with the S4CNL experimental model
Notations:

$\lambda_{\mathrm{e}}$ - specific speed (TSR - tip speed ratio);

$\mathrm{v}$ - wind speed, $\mathrm{m} / \mathrm{s}$;

D - Diameter, m;

$\mathrm{H}$ - Height, $\mathrm{m}$.

Abbreviations:

RES - Renewable Energy Sources;

HAWT - Vertical Axis Wind Turbine;

EM - Experimental Model;

S2PCiNL - Savonius 1 pair of Cups Interlaced No

Load;

S2CNL - Savonius 2 Cups No Load;

S3CNL - Savonius 2 Cups No Load;

S4CNL - Savonius 2 Cups No Load.

Under these conditions, an experimental model of VAWT was proposed (see previous paper [3]) in which the deficiencies of using two diametrical cylindrical cups can be eliminated by using 4 cups, two by two diameters and their aerodynamic coupling by overlap and gap. This creates a channel for equalizing the pressures on the buckets in the maximum torque position, reducing the resistant torque on the return stroke. The practical realization of these channels for the pairs of coupled blades was done by dividing the height of the model and interweaving the coupled blades (Fig. 1).

The same mathematical model of wind energy [6] generated in the tunnel and the same mathematical model of the conversion of wind energy into mechanical work as in the paper are used $[3,5,7]$.

The limits of the efficiency of converting wind energy into mechanical work on the shaft are taken into account, a situation specific to Savonius type vertical shaft wind turbines, which leads to a Betz limit of $14.81 \%$.

Although it has a low value of efficiency, this type of wind turbines has a constructive simplicity, a situation that is corroborated and with the increase of the use of electricity obtained can lead to independent sources in important but isolated areas.

\section{Experiments}

The resulting experimental model (EM) has the same wind interception area (maximum $10 \%$ of the cross-sectional area of the wind tunnel measurement area) respectively $0.025 \mathrm{~m}^{2}$. Dimensions of the model: diameter $\mathrm{D}=0.157 \mathrm{~m}$, height $\mathrm{H}=0.157 \mathrm{~m}$.

The experiments were performed in a wind tunnel with an adjustable speed between $0-10.5 \mathrm{~m} / \mathrm{s}$, which has a measuring section of $0.5 \mathrm{~m} \times 0.5 \mathrm{~m} \times$ $1.25 \mathrm{~m}$. The wind speed was measured with an LCA6000 anemometer. The experimental model was fixed in point bearings (peaks) and the speed of the experimental model was taken with IR sensor and 
slotted disk with the ATMEL 328U Microprocessor and recorded with SerialPlot.

The experimental regimes involved a gradual change in the speed of the wind tunnel fan and a decrease in the wind speed from the maximum value to the value at which the model no longer rotates.

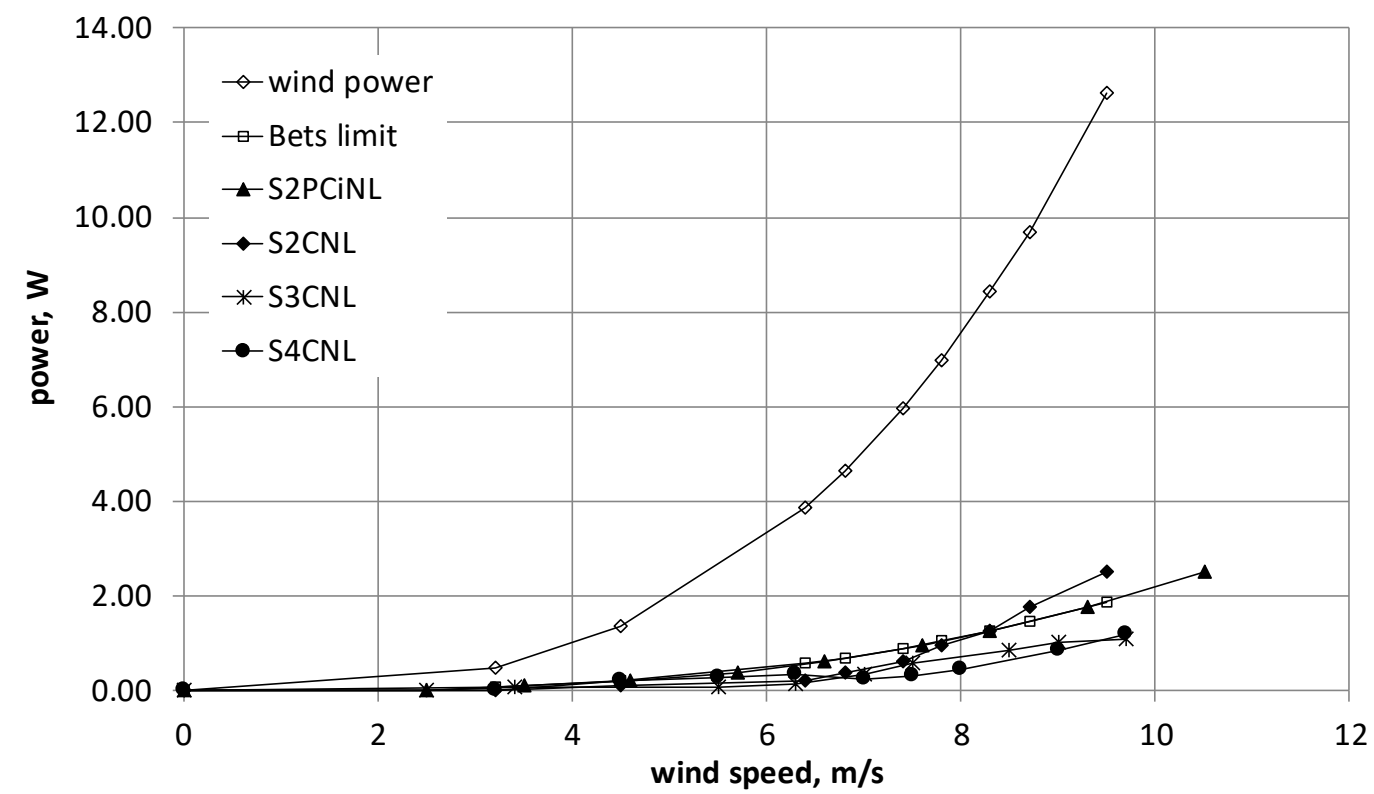

Fig. 5. Wind power, Betz limit and shaft powers of the considered and reference model

\section{Results and discussions}

The results of the tests performed in laboratory conditions on the wind tunnel are shown in Figures 514.
Figure 5 shows the wind power, the Betz limit and the axis powers of the considered model and the reference ones. It is observed that the Betz limit for this type of wind turbine based on drag force is according to theory $14.81 \%$. At high wind speeds the S2PCiNL exceeds this limit, which implies the appearance of other mechanisms besides Drag force.

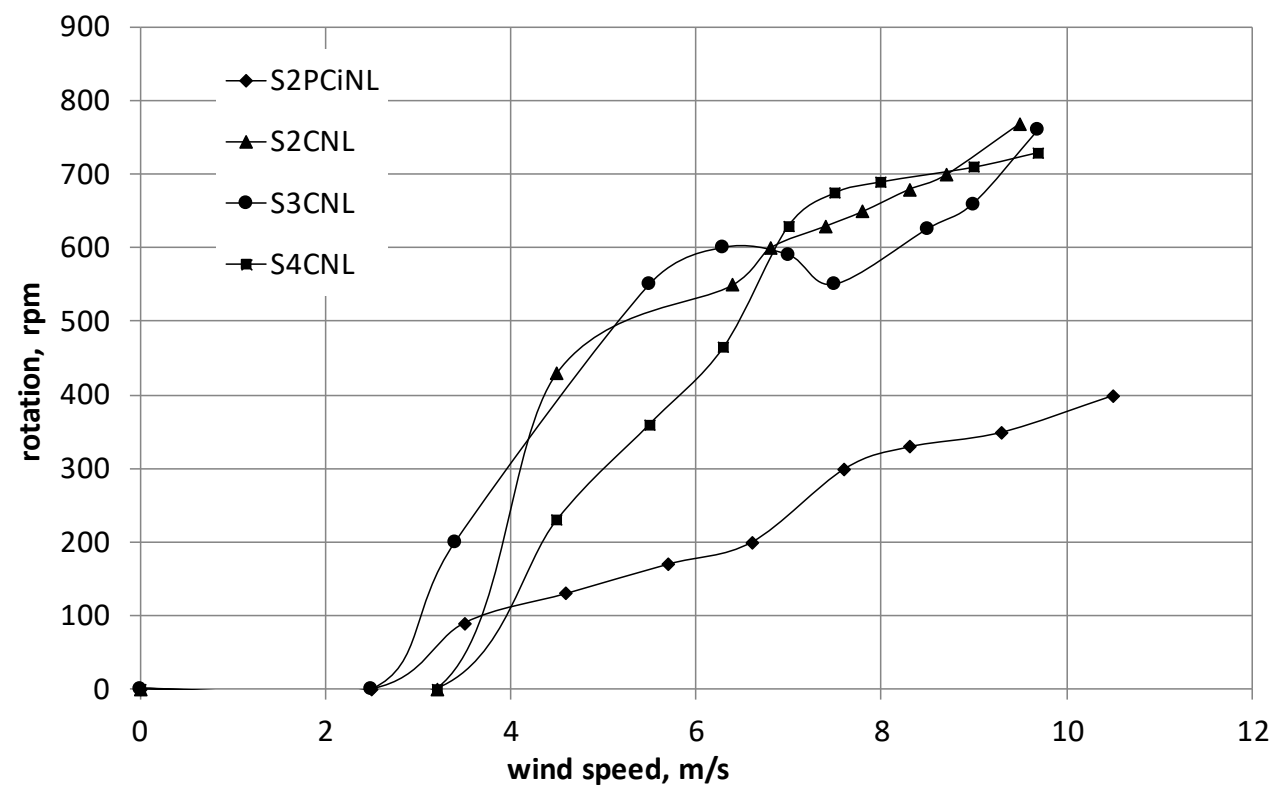

Fig. 6. Rotation speed variation for S2PCiNL and experimental S-rotor reference models 

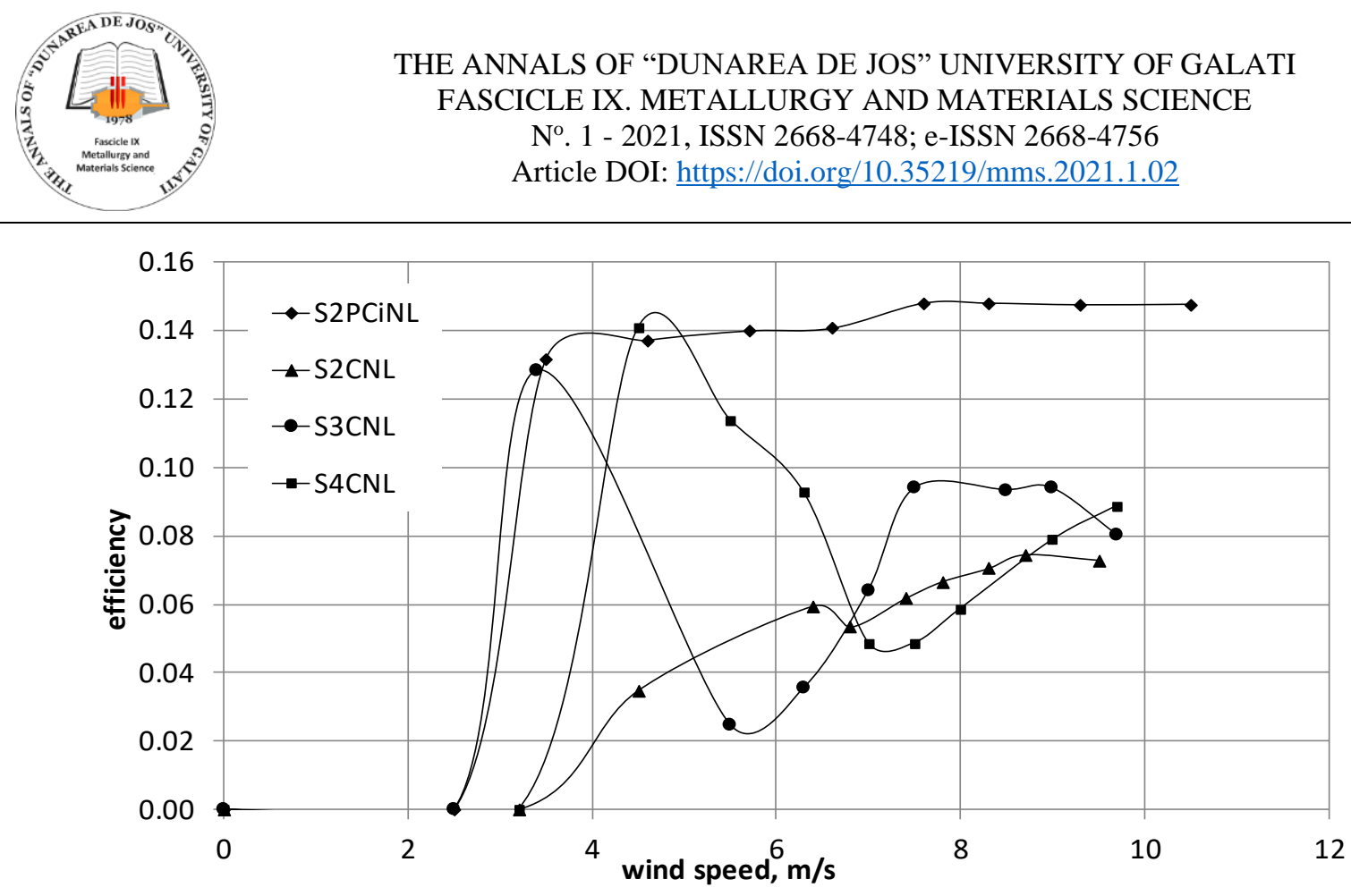

Fig. 7. Variation of conversion efficiency for S2PCiNL and reference S-rotor experimental models

The studied experimental model (S2PCiNL) has a good sensitivity regarding the minimum speed at which the rotation starts $(2.5 \mathrm{~m} / \mathrm{s})$ compared to the Savonius models taken as reference (Fig. 6). A similar behavior has EM Savonius with 3 semicylindrical cups, but it has a different behavior from other points of view. Even in terms of wind speed rotation. EM Savonius has an oscillating behavior even if it has a higher rotational speed than the model considered at the same wind speed. The S2PCiNL speed increases approximately linearly from $0-400$ rpm for wind speed 2.5 to $10.5 \mathrm{~m} / \mathrm{s}$ (Fig. 6).

In Fig. 7 is showing variation of conversion efficiency for S2PCiNL and reference S-rotor experimental models.

An important observation (Fig. 7) is regarding the efficiency of the conversion of wind energy into mechanical work which has a narrow range of variation between 0.14 and 0.148 for values of wind speed from $3 \mathrm{~m} / \mathrm{s}$ to $10 \mathrm{~m} / \mathrm{s}$.

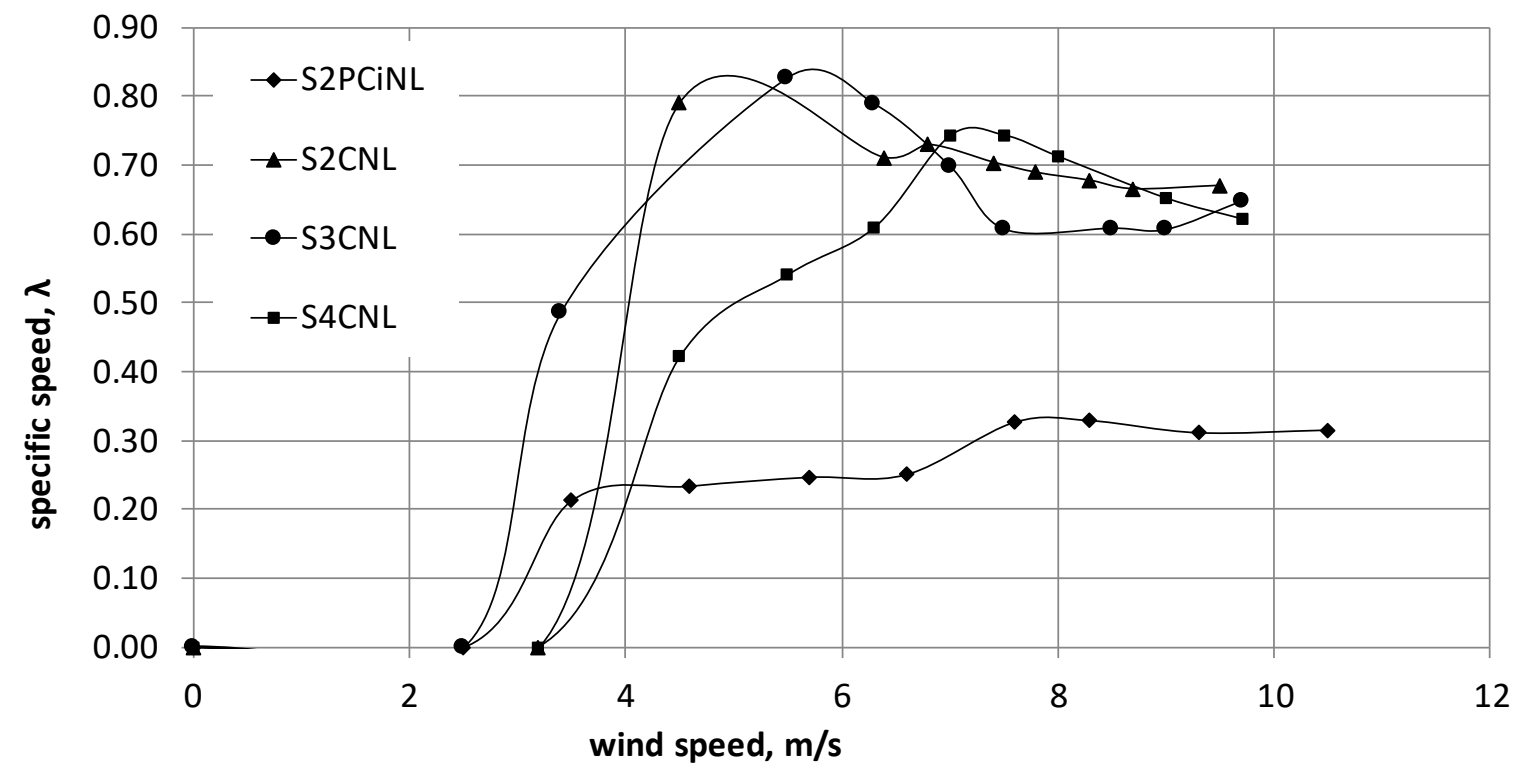

Fig. 8. Wind speed specific speed variation for S2PCiNL and experimental S-rotor reference models 


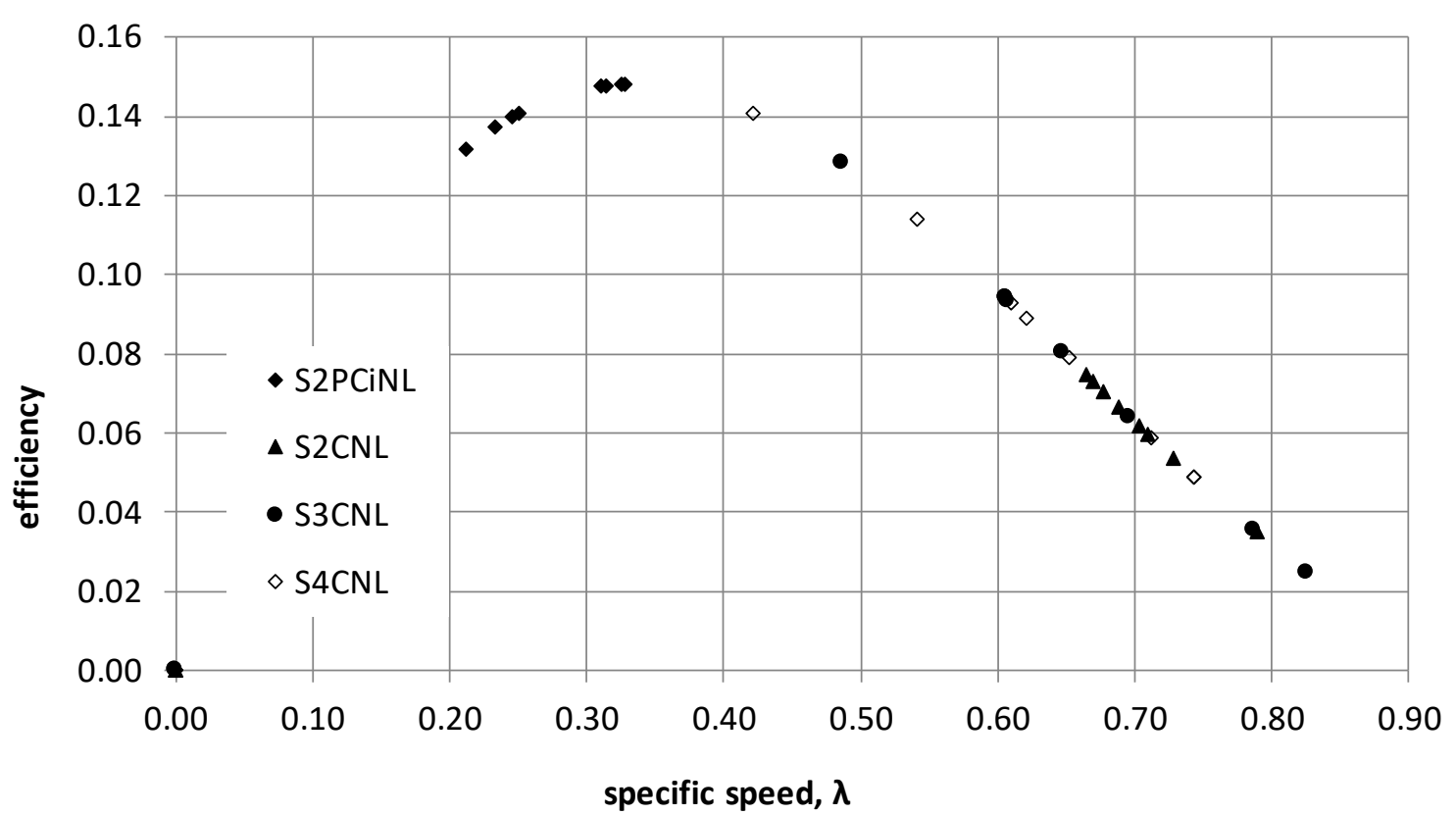

Fig. 9. Efficiency variation with specific speed for S2PCiNL and for experimental S-rotor reference models

A very important parameter regarding the operation of wind turbines is the specific or relative speed.

In Fig. 8 is showing specific wind speed variation for S2PCiNL and for the reference S-rotor experimental models. The very different behavior of the experimental model S2PCiNL towards dew references is observed. Thus, the specific speed is lower $0.22-0.32$ but remains almost constant over a range of wind speed variation from $3.5 \mathrm{~m} / \mathrm{s}$ to 10.5 $\mathrm{m} / \mathrm{s}$

It is observed (Fig. 9) that the efficiency of the considered experimental model (S2PCiNL) is close to the maximum value of this type of wind turbine but is obtained at low speeds of the specific speed (0.2-0.3) which shows the special behavior of this type of experimental model. For the other Savonius turbine models taken as a reference, the efficiency is deviated from the maximum value.

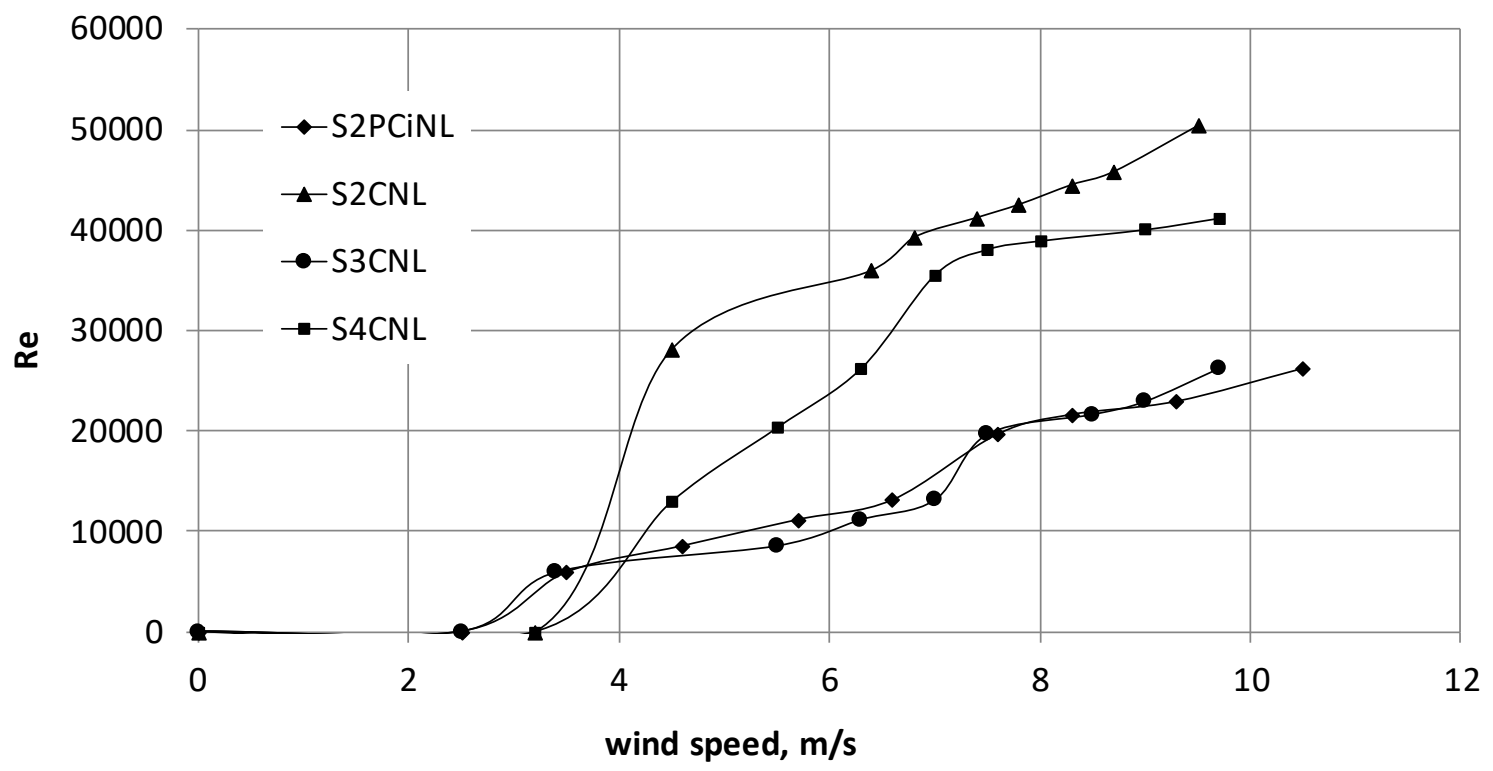

Fig. 10. Re number variation with wind speed for S2PCiNL and for experimental S-rotor reference models 

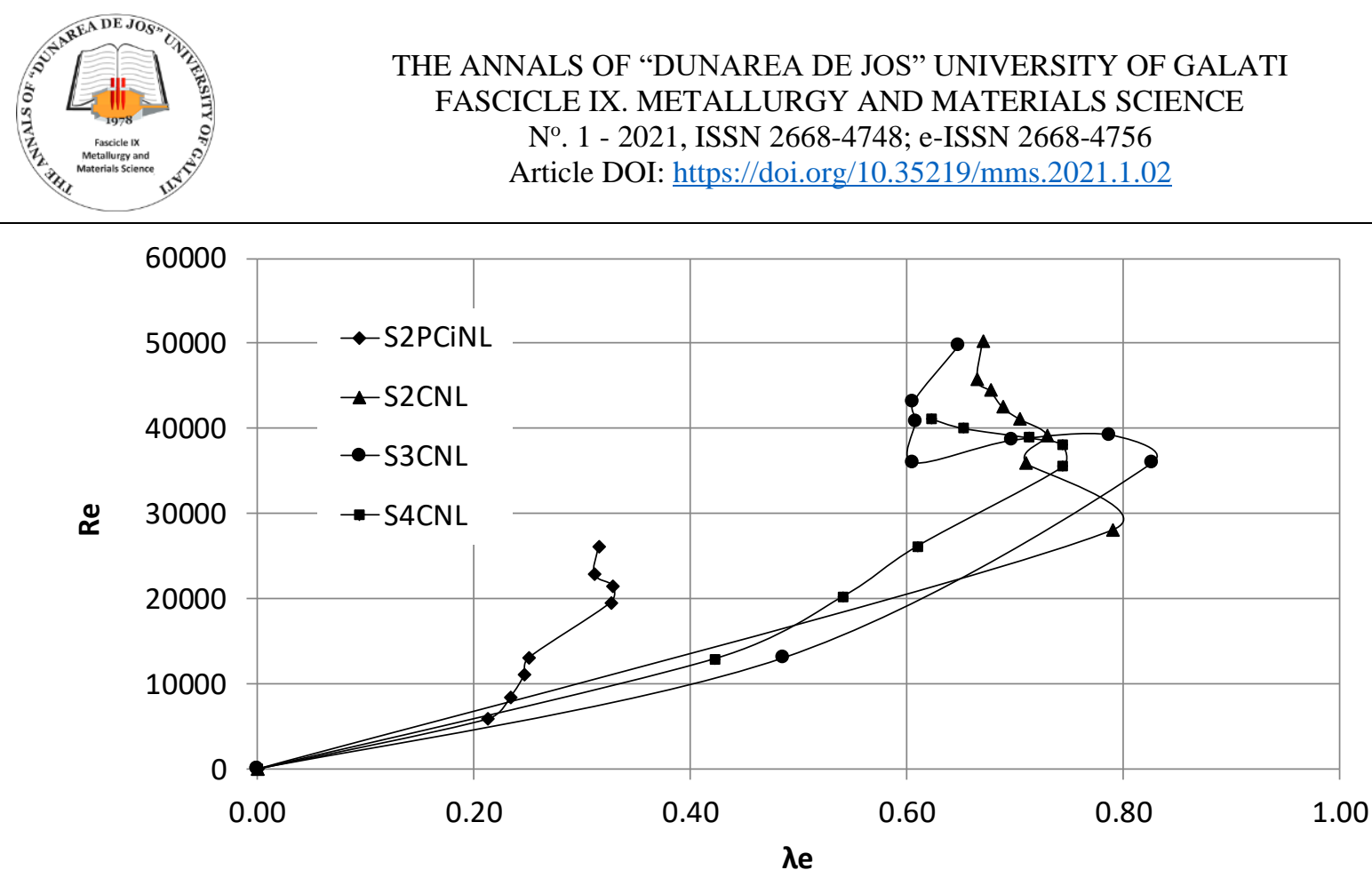

Fig. 11. Specific speed Re number variation (TSR) for S2PCiNL and S-Rotor experimental reference models

From the point of view of the variation Re number for S2PCiNL it is observed in Fig. 10. The behavior is very close to S3CNL and very different from S2CNL and S4CNL. For the considered model RE number varies almost linearly from $0-25000$ for wind speed between 2.5 and $10 \mathrm{~m} / \mathrm{s}$.

Compared to their equivalent speed, Re number has a much different variation than for the experimental S-rotor models taken as reference (Fig. 11). Thus, if for the experimental models S-rotor reference with 2,3 and 4 cups Re number have maximum values between 30000-50000 for the specific speed 0.6-0.8 for the experimental model Re number does not exceed 25000 for a narrower speed range around 0.3 .

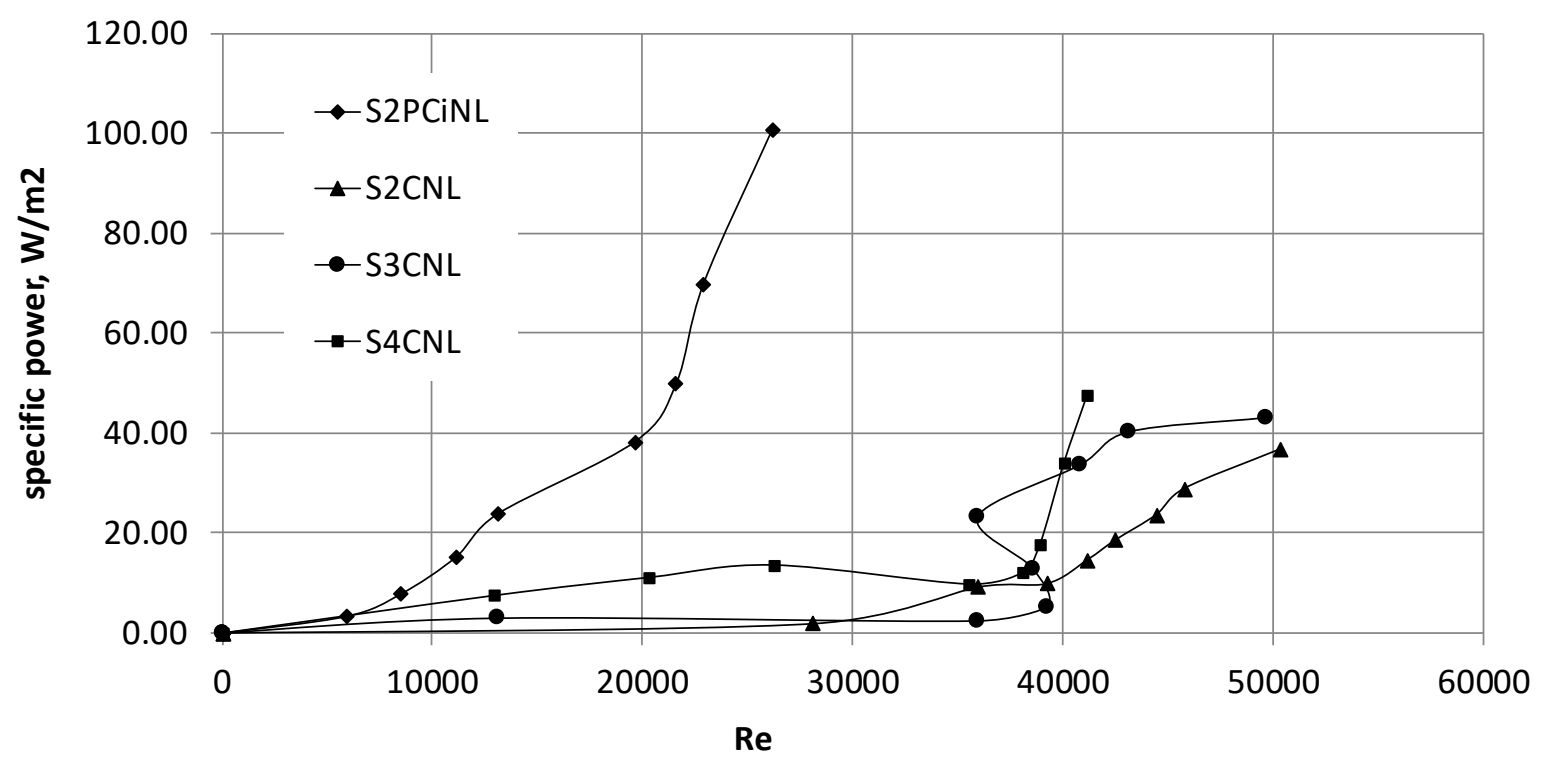

Fig. 12. Shaft specific power according to Re number for S2PCiNL and for experimental S-rotor reference models 

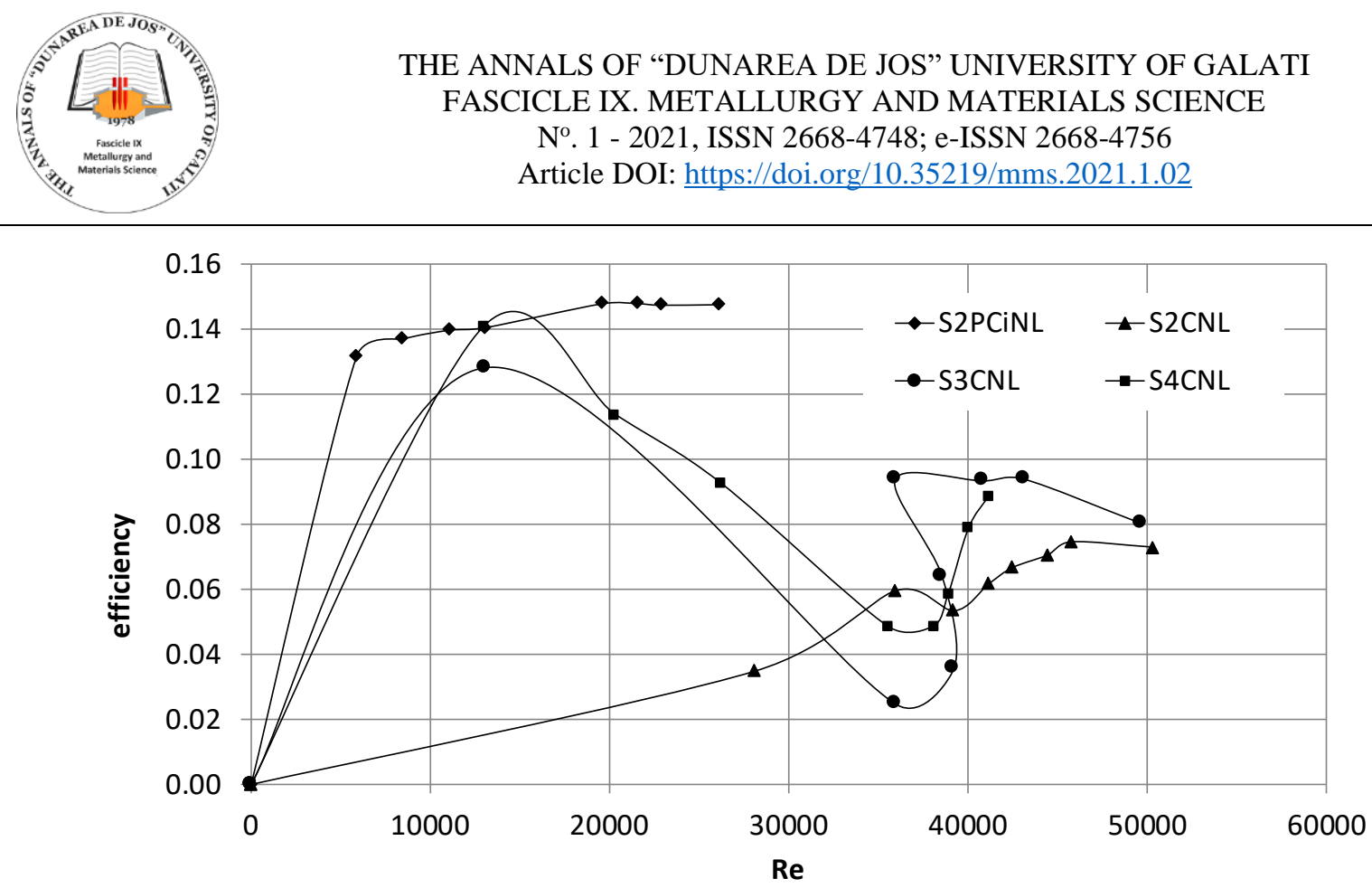

Fig. 13. Efficiency of the experimental model S2PCiNL and for experimental models $S$-rotor reference function Re number

Fig. 12 shows the specific shaft power depending on the Re number for S2PCiNL and for the experimental S-rotor reference models. The different behavior of the S2PCiNL experimental model is observed which has a specific power at the shaft that exceeds 2.5 times at Re number by half.

And the efficiency of the studied experimental model (S2PCiNL) with Re Number shows different behavior than for the reference S-rotor experimental models (Fig. 13). It is close to the maximum value of the Betz limit, but more importantly it has a high value on a line that increases in a range of Re number from 5000 to 25000. In Fig. 14 show the variation of the specific shaft power with wind speed for S2PCiNL and for the experimental reference S-rotor models. It is observed that the specific power at the shaft is the highest of the models considered, which is an important premise regarding the experiments that will be performed on this model with mechanical and electrical loads.

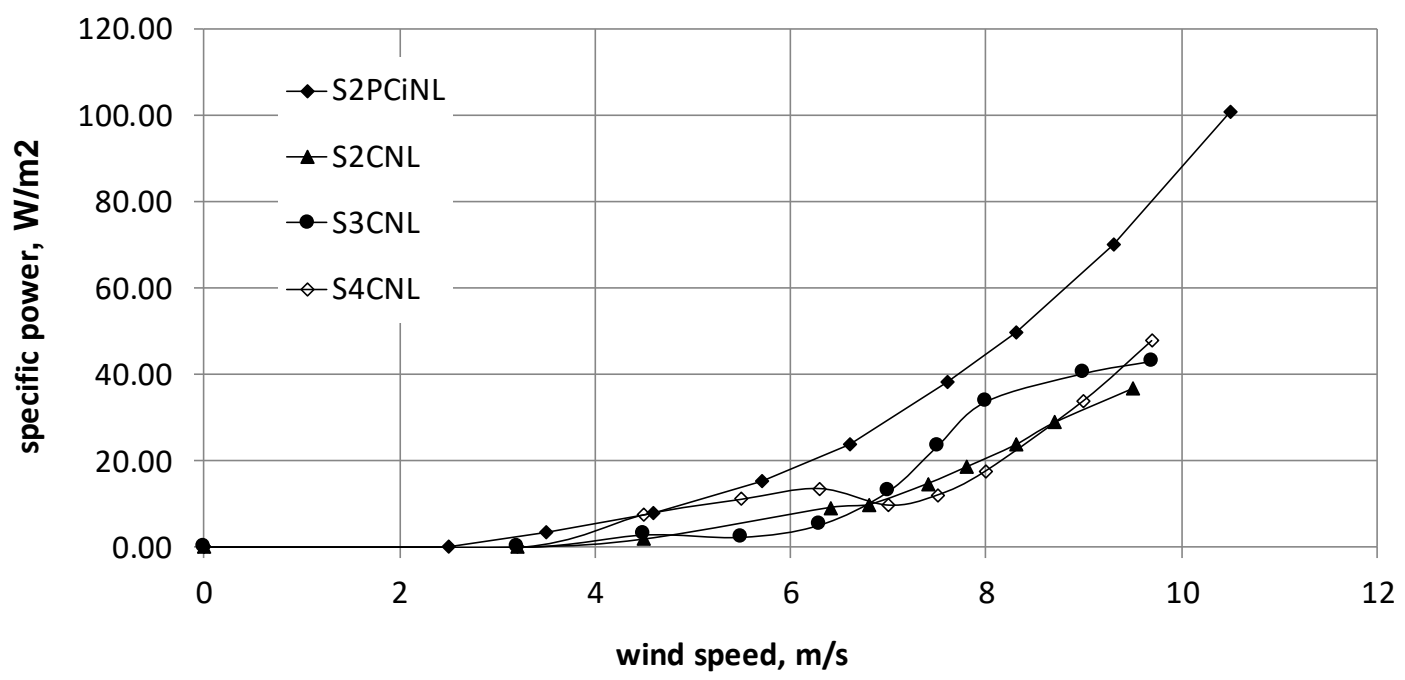

Fig. 14. Shaft specific wind power variation for S2PCiNL and reference S-rotor experimental models

\section{Conclusions}

The experimental model (Fig. 1) studied in the wind tunnel up to speeds of $10.5 \mathrm{~m} / \mathrm{s}$ falls within the Betz limit up to WIND speeds lower than $8.5 \mathrm{~m} / \mathrm{s}$ then exceeds this limit, which shows the existence of other mechanisms which produce the rotational motion other than drag force D (Fig. 5). The rotation speed increases linearly from $2.5 \mathrm{~m} / \mathrm{s}$ to $10.5 \mathrm{~m} / \mathrm{s}$ (Fig. 6) but is lower than the experimental models of 


\section{THE ANNALS OF “DUNAREA DE JOS” UNIVERSITY OF GALATI \\ FASCICLE IX. METALLURGY AND MATERIALS SCIENCE \\ $\mathrm{N}^{\circ} .1$ - 2021, ISSN 2668-4748; e-ISSN 2668-4756 \\ Article DOI: https://doi.org/10.35219/mms.2021.1.02}

Savonius turbine with 2, 3 and 4 semi-cylindrical buckets (Fig. 2, Fig. 3 and Fig. 4). The specific lambda speed (Fig. 8) has values between 0.2-0.3 for wind between $3.5-10.5 \mathrm{~m} / \mathrm{s}$, almost 2-3 times lower than the maximum value of the reference EMs. Due to the low rotation Re number has lowers values but increases linearly with wind speed (Fig. 10). This is also confirmed by the variation of $\mathrm{Re}$ number with the specific velocity $\lambda_{\mathrm{e}}$ (Fig. 11) which shows much lower values than the experimental models referred to. The conversion efficiency to mechanical work has values over $14 \%$ for wind speeds of $4-10.5 \mathrm{~m} / \mathrm{s}$. The experimental model S2PCiNL has the best efficiencies of conversion to mechanical work (Fig. 9) and for a wide range of $\mathrm{Re}$ number between 10000 and 25000 (Fig. 13). The specific power at the shaft (Fig. 12 and Fig. 13) shows maximum values of 100 $\mathrm{W} / \mathrm{m}^{2}$ at Re number 25000 and at wind speed of 10.5 $\mathrm{m} / \mathrm{s}$. Stable and uniform operation in a range of wind speeds and efficiency at no load are prerequisites for good performance in load tests.

\section{References}

[1]. Badea Nicolae, et al., Sistem integrat de poligenerare descentralizata a energiei din surse regenerabile, $\mathrm{CBI}$ A/00402/2011, 29 Aprilie 2011.

[2]. Cazacu Nelu, Renewable Energy Sources for the mCCHP-SERES System, [autorul cărții] Badea N (ed). Design for Microcombined Cooling Heating and Power System, London: Springler, 2015.

[3]. ***, Experimental Model of Wind turbime with Vertical Axis, Multy-Storey and with two Pairs of Blades on level Aerodynamic Coupled, The Annals of "Dunarea de Jos" University of Galati, Fascicle IX, Metallurgy and Materials Science, vol. 2, p. 21-26, ISSN 2668-4748, e-ISSN 2668-4756, 2019.

[4]. Menet J. L., Bourabaa N., Increase in a savonius rotor efficiency.

[5]. Cazacu Nelu, Improving the Powerful Behavior of an ExperimentaL model of Savonius Turbine (S-rotor) with Couple Aerodynamic Additional Blades, The Annals of "Dunărea de Jos" University of Galati, Fascicle IX, Metallurgy and Materials Science, Galati University Press, vol. 2, p. 49-53, ISSN 1453 083X, 2018.

[6]. Hau Erich, Wind Turbines, Fundamentals, Technologies, Applications, Economics, s.1.: Springler, 2006.

[7]. Cazacu, Nelu, Load Behavior of a Vertical Axle Wind Turbine Model with Four Blades Periodically Couple Aerodynamically, The Annals of "Dunarea de Jos" University of Galati, Fascicle IX, Metallurgy and Materials Science, Galati University Press, vol. 3, p. 5-11, ISSN 2668-4748, e-ISSN 2668 4756, 2018. 